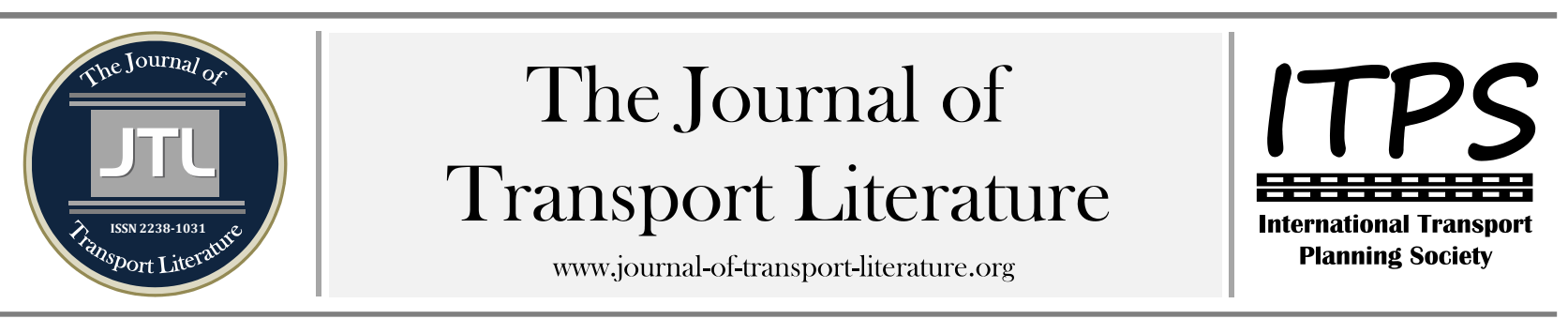

\title{
Binomial logistic regression model of household motorcycle ownership in Akure, Ondo State, Nigeria
}

Olugbenga Joseph Oyedepo+; Japheth Etu

Federal University of Technology Akure, Akure, Nigeria

\section{Article Info}

Keywords:

Binomial Logistic Regression Density

Household

Motorcycle

Transportation

Submitted 23 Jan 2015 received in revised form 8 May 2015 accepted 11 May 2015.

Licensed under

Creative Commons

CC-BY 3.0 BR.

\section{Abstract}

In order to forecast and make provisions for future demand of motorcycle in Akure, there is a need to understand factors driving motorcycle ownership, therefore, this study examines factors which affect motorcycle ownership in Akure metropolis. Three different zones namely, Low Density (LD), Medium Density (MD) and High Density (HD) were considered,, both close-ended and open-ended questionnaire were administered to 900 households representing $75 \%$ of the total population. Using Statistical Package for Social Sciences version 16 data were analyzed and binomial logistic regression analysis was used in developing a model which showed that only academic qualification of household head, number of household members and average monthly income of household significantly influences motorcycle ownership across the zones at the 95\% confidence level. Both average monthly income of household and academic qualification of household head had a negative influence on motorcycle ownership whereas number of household members had a positive relationship with motorcycle ownership. The results shows that there is a 1.43 times likelihood of owning a motorcycle with a unit increase in the number of household members, while there is a reduction in the likelihood of owning a motorcycle by 1.66 times and 2.17 times for a unit increase in the average monthly income and academic qualification of household head respectively. The results obtained can be used in developing policy framework to improve public transport and control motorcycle ownership in the city of Akure.

+ Corresponding author. Federal University of Technology Akure, Akure, Nigeria.

E-mail address: oyedepoo@yahoo.co.uk.

\section{Introduction}

Transportation is a process that involves the movement of commuters, goods and services from a given point of origin to a specific destination (Okoko, 2006), it determines the regional patterns of development, economic viability, environmental impacts and maintenance of socially acceptable levels of quality of life. It is a means to access business activities, education, employment and recreational opportunities, thus contributing to policy effectiveness and enhancement of security through reduced isolation as well as providing job opportunities (World Bank, 2002). In developing cities of the developing world, enhanced mobility for the poor and vulnerable groups is one of the most important preconditions for achieving Millennium Development Goals. In cities such as China, Thailand, Malaysia, Ghana, and Nigeria, motorcycles play a significant role in the daily travel pattern of the people. In Nigeria, motorcycle popularly called Okada is widely used in villages, towns and major cities including Akure. Due to the small size and the engine capacity of 100-150cc, motorcycles have higher mobility, particularly on the congested road. People use motorcycles for either short or long distance trips over many trip purposes including work, shopping, leisure, and education. This is as a result of poor services of the existing public transport and motorcycle is more practical to cope with traffic congestion and more efficient compared to either private cars or public transport (Tuan and Shimizu, 2005). As a result of the aforementioned reasons, the advantages which motorcycle posess and its continuous as a means of transportation. This article therefore investigates the factors which influence household motorcycle ownership in Akure metropolis.

In Akure, the traffic composition is mixed comprising of motorcycles, taxis, minibuses, Lorries and trucks (trailers). It is dominated by taxis, motorcycles (Okadas) and minibuses (Owolabi, 2009). Also, in the study by Oyedepo (2014) 49.82\% of the vehicle sample is car/taxi, $39.87 \%$ are motorcycle, and $9.37 \%$ are buses, while 2axle- load and 3axle-load are $0.73 \%$ and $0.21 \%$ respectively. Thus, passenger cars and motorcycles falls among the dominant mode of transportation. This high number of motorcycle ownership, motorcycle accidents as well as traffic problems posed by its use indicates the need for this study. In order to deal with traffic problems posed by motorcycles and better formulate policies regarding its use, this study sets out to investigate motorcycle ownership by understanding the owning behavior. Thus, the primary objective is to analyze household motorcycle ownership in Akure using Logistic Regression Model.

In the study, a brief literature review is given in Section 1, section 2 describes the study area and this is followed by a description of the methodology for the study in Section 3. In Section 4 the results of the analyses were discussed and the developed model presented with relevant conclusions drawn. 


\section{Literature Review}

In Nigeria, the government's inability to provide conventional mode of transport has necessitated the use of motorcycles (two-wheeled automobiles) and tricycles (three-wheeled automobiles) to move people, goods and services from one point to another under conditions considered to be unsafe and accident prone. It started as common mode of intra-city transport in the riverine areas of Delta, Edo, Cross-river, Rivers, and Akwa-Ibom States of Nigeria, partly due to the water logged nature of these areas, which latter spread to other cities in other parts of the country where it is now used for intra-city movement of people and goods on commercial basis. Motorcycles have now invaded the suburbs and inner cities, towns and local areas of the country as big commercial transport business [Oyesiku, and Odufuwa] [Fasakin, (2001)].

A combination of factors can be identified as responsible for the use of motorcycles (Okada) as means of intra-city transport in Nigeria. One important factor was the rapid rate of urbanisation in the face of inadequate means of transportation. Commuters often struggled at peak periods for commercial vehicles to convey them in or out of their areas (Ikeano, 1991). Olubomehin (2012) examined the development and impact of motorcycles as means of commercial transportation in Nigeria. He identified rapid rate of urbanization in the face of inadequate means of transportation, high rate of unemployment prevalent in the country in the 1980s as a fall-out of the downturn in the Nigerian economy at this period and the relative lucrative nature of commercial motorcycle business as factors responsible for the growth of motorcycle business in Nigeria. Aderamo (2013) cited the poor state of roads in many developing countries and the inability of bus companies to meet growing demand as factors responsible for the use of motorcycles for commercial transport.

The advantage which motorcycles has over other transport modes accounted for its use for commercial transportation. Some of these advantages are that it can get to areas where commercial vehicles may access due to bad road, there is no road that is too narrow and there is no area too remote for motorcycles, they are able to take passengers to their door steps, they are faster and save time than other means of transportation, because they are capable of maneuvering their way through traffic congestion. On the other hand, motorcycle is cheaper to maintain than other modes of transportation, since it consumes lesser fuel and the spare parts are cheaper. Thus, the rate of urbanization, poor government policies and a host of socio economic variables are contributory factors influencing ownership and widespread growth of motorcycles in developing cities like Akure.

Several studies had been conducted on the use of motorcycles; Ogunsanya and Galtima (1993) did a study on the use of motorcycle as a means of public passenger traffic in Yola town, Adamawa State. They identified economic depression and inadequate transport facilities as some of the factors that gave rise to the use of motorcycles as means of public transportation in Nigeria. Also, Tuan and Shimizu (2005) in their study in Hanoi city Vietnam on household motorcycle ownership behaviour, using a retrospective survey to collect household motorcycle transaction process, while heterogeneity was analysed using random coefficients logit model, the results showed that increases in number of workers or students, motorcycle price, income, and previous transactions significantly influence current transaction decisions and that sufficient high taxes imposed on motorcycle users could be effective in controlling the ownership.

Sadullah et al (2006) conducted a study in Penang, Malaysia using multinomial logit model to examine motorcycle ownership. They affirm that total monthly household income, car ownership, total number of driving licenses in the household and number of household members influenced motorcycle ownership. The study concluded that motorcycle will remain the mode of transport in the near future, particularly in the group of low and middle income households.

In another study, Hsu and Lin (2007) in Taipei Taiwan; they investigated both car and motorcycle ownerships with 336 samples using multinomial logit model. The study was based on the assumption that when both a car and a motorcycle are owned by the same household each will have a relation of substitution. The study concluded that the main reason for motorcycle and a car was not cost, but utility factors. The increase in reliability as well as convenience of a car increase car ownership between $12 \%-29 \%$ and while it reduces motorcycle ownership.

\section{The Study Area}

Akure is a traditional Nigerian city and like other traditional Yoruba towns in the country, it existed long before the advent of British colonial rule in the country. The city is located within Ondo State in the South Western part of Nigeria. Akure with the provisional census figure of 387,087 people according to 2006 national population census, is located on latitude $7020 " \mathrm{~N}$ and longitude 50"E. The natural pattern of development is linear along its main roads vizOyemekun-Oba Adesida road and Arakale-Oda road. The existing land use is characterized by a medium density of structure within the inner core areas. Akure is mostly residential areas forming over $90 \%$ of the developed area but additional activities such as warehousing, manufacturing, workshops and other commercial uses are commonly located within the residential neighborhoods. The present traffic composition of Akure is dominated by taxis, Okadas and minibuses. Figure 1 is the map of Akure showing the study locations. 


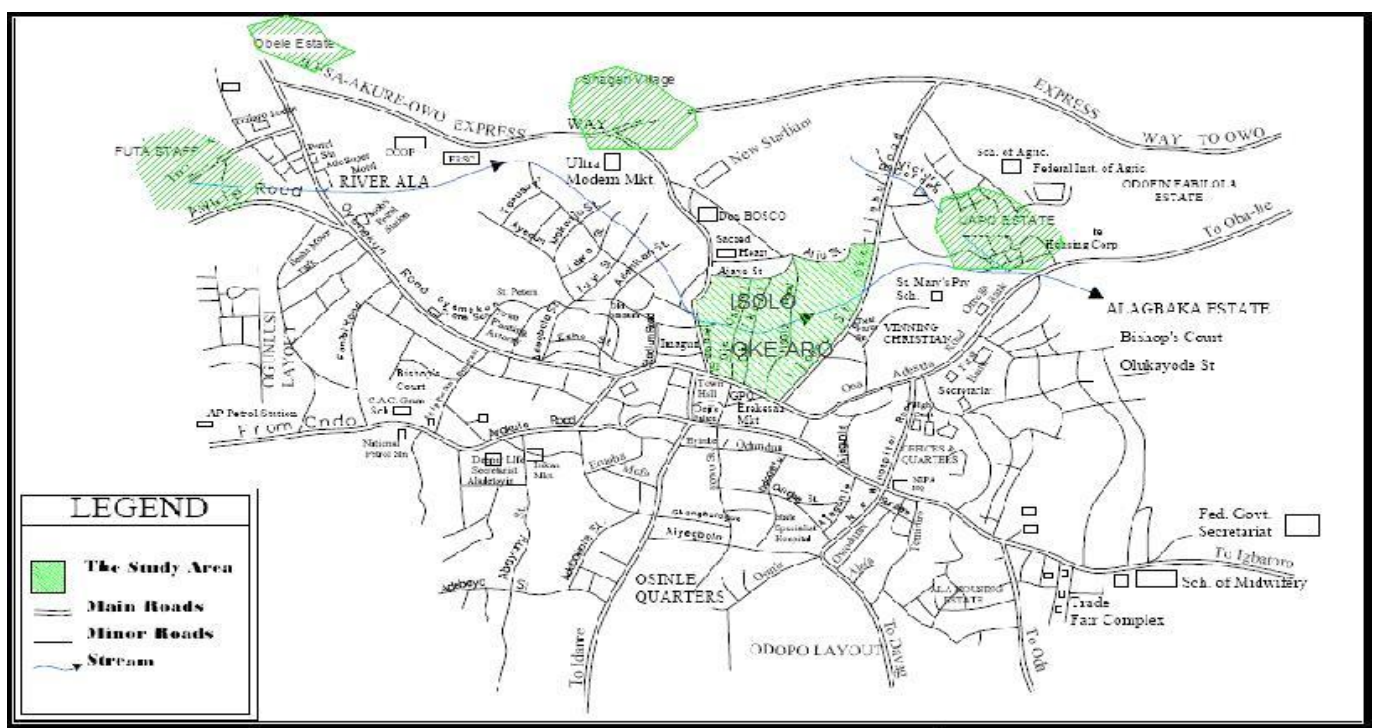

Figure 1 - Land use Map of Akure showing the Study Locations. Source: Ogunmoriti \&Ige (2013)

\section{Methodology}

Reconnaissance survey of the study area was conducted to assess the socio-demographic characteristics of the household. Three different zones coded as shown in Table 1 were selected and classified base on their population density (land use). Data for the study was sourced both from field surveys (primary data) and relevant road transport agencies (secondary data). The primary data were sourced through the administration of a structured questionnaire to various household members for a period of 30 days between November to December 2014.. The calculation for sample size was based on the consideration to examine at least half (50\%) of the total study population. A total of 900 household comprising of 300 per zones were served with questionnaires which represents $75 \%$ of the total population. This was selected through triangulation of sampling methods and cuts across all the selected location.

The needed data was obtained through primary source and this involved the use of both questionnaire and in-depth interview. The questionnaire consist of questions with options from which respondents are expected to pick response as applicable (close-ended) and questions which allow respondents to freely express their opinion on the subject matter (open-ended), both univariate analysis (that is, frequency distribution and percentages) and content analysis to complement the survey findings was employed for this study. Only six hundred and twelve (612) questionnaires were retrieved for data analysis, which represent $68 \%$ of the total population as shown in Table 1 . However, data obtained from different zones based on land use was analyzed using Statistical Package for Social Sciences version 16 (SPSS 16) the resulting model was developed using Binomial Logistic Regression Model.

Binomial logistic regression predict the probability that an observation falls into one of two categories of a dichotomous dependent variables base on a set of categorical or continous independent variables. It is useful for situations in which you want to be able to predict the presence or absence of a characteristic based on values of a set of predictor variables i.e when the dependent variable is dichotomous. The binomial logistic regression model was adopted in the study because the dependent variable has two levels of responses (YES vs. NO) to motorcycle ownership. The results obtained from the analyses of field survey data are shown and discussed in section 4.

Table 1- Selected Study Zones in Akure

Source: Author's own field survey data

\begin{tabular}{|c|c|c|c|c|}
\hline \\
\hline Zone & Location & $\begin{array}{l}\text { No.of } \\
\text { Questionnaires } \\
\text { Returned }\end{array}$ & $\begin{array}{l}\text { Percentage of the } \\
\text { Respondent per } \\
\text { Location }\end{array}$ & $\begin{array}{l}\text { Percentage of } \\
\text { the } \\
\text { Respondent } \\
\text { per Zone }\end{array}$ \\
\hline \multirow[b]{2}{*}{$\begin{array}{l}\text { High } \\
\text { (HD) }\end{array}$} & Oke Aro (HD 1) & 176 & $28.75 \%$ & \multirow[b]{2}{*}{$50.65 \%$} \\
\hline & Araromi (HD 2) & 134 & $21.89 \%$ & \\
\hline \multirow[b]{2}{*}{$\begin{array}{l}\text { Medium Dens } \\
\text { (MD) }\end{array}$} & Orita-Obele (MD 1) & 111 & $18.14 \%$ & \multirow[b]{2}{*}{$37.58 \%$} \\
\hline & $\begin{array}{l}\text { FUTA Community } \\
\text { (MD 2) }\end{array}$ & 119 & $19.44 \%$ & \\
\hline \multirow[t]{2}{*}{ Low Density (LD) } & Ijapo Estate (LD 1) & 26 & $4.25 \%$ & \multirow{3}{*}{$11.76 \%$} \\
\hline & Alagbaka (LD 2) & 46 & $7.52 \%$ & \\
\hline Total & & 612 & $100 \%$ & \\
\hline
\end{tabular}




\section{Result}

The percentages of motorcycle ownership obtained as shown in Table 1 are $11.76 \%, 37.58 \%$ and $50.65 \%$ at the low, medium and high density zones respectively. This indicates that motorcycle is predominantly used in the high density zone. The analysis depicted in Figure 2 also reveals 11.52\% owned motorcycle because it is more convenient and reduces travel time; while $75.09 \%$ and $3.72 \%$ respectively owned motorcycle because it is affordable and due to ineffective transportation. However, $9.67 \%$ of the respondent owned motorcycle for personal reasons.

where: X1 represents number of respondent that says motorcycle in more convenient and reduce travel time;

$\mathrm{X} 2$ = number of respondent that cannot afford car;

$\mathrm{X} 3$ = ineffective transportation; and

$\mathrm{X} 4=$ other reasons

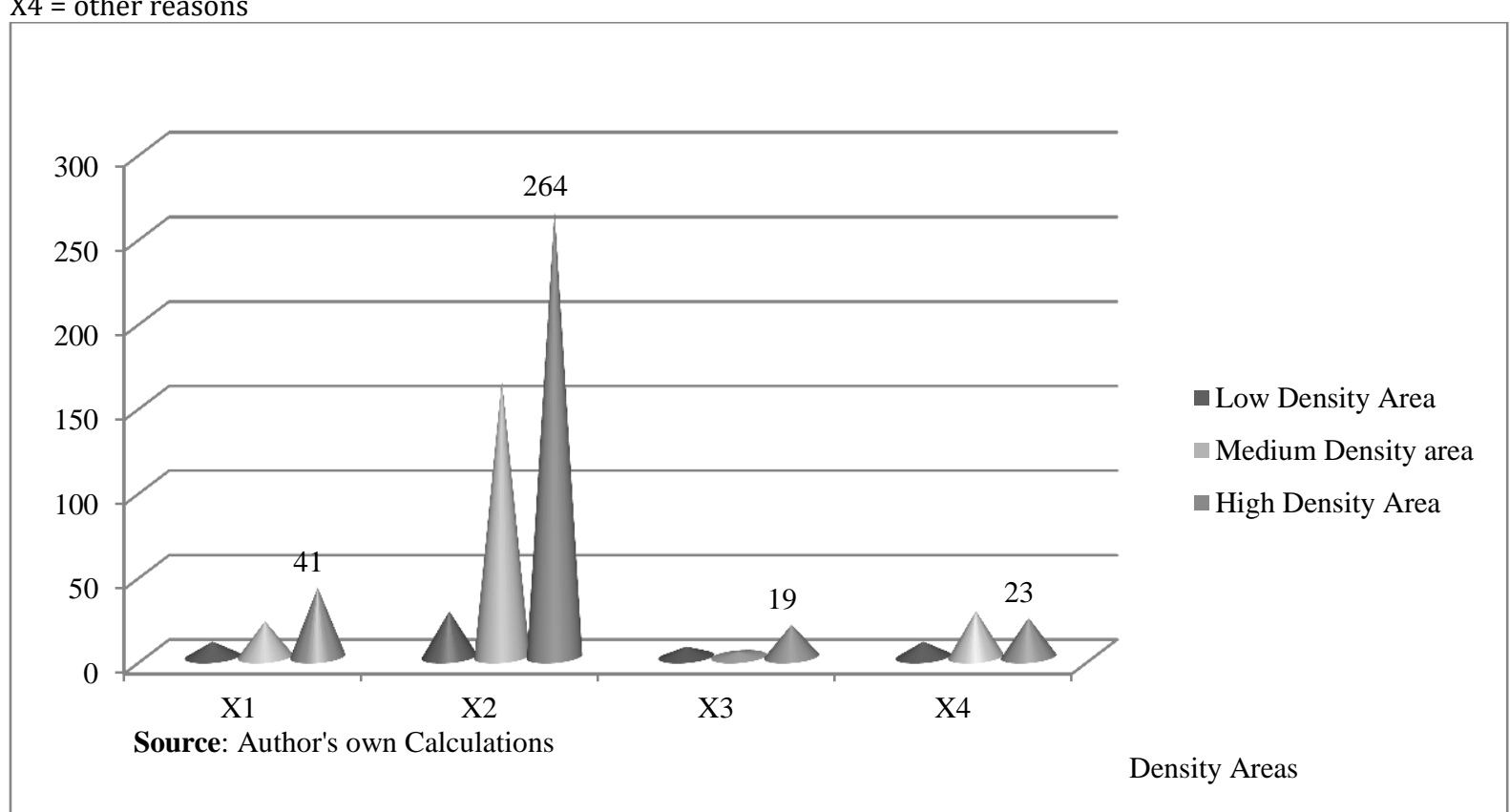

Figure 2 - Reasons for owning motorcycle

Binomial Logistic Regression Model: Table 2 is the summary of the binomial logistic regression model, while Table 3 is the model summary.

Table 2 - Binomial Logistic Regression Model Source: Author's own Calculations

\begin{tabular}{|c|c|c|c|c|c|c|c|}
\hline & & B & S.E. & Wald & df & Sig. & $\operatorname{Exp}(B)$ \\
\hline \multirow[t]{6}{*}{ Step 1a } & AGE & -.196 & .129 & 2.322 & 1 & .128 & 1.217 \\
\hline & Academics & -.775 & .096 & 65.064 & 1 & .000 & 2.171 \\
\hline & Household-members & .357 & .061 & 34.142 & 1 & .000 & 1.429 \\
\hline & Income & -.508 & .116 & 19.246 & 1 & .000 & 1.662 \\
\hline & Distance & -.107 & .118 & .828 & 1 & .363 & .898 \\
\hline & Constant & -5.779 & .552 & 109.739 & 1 & .000 & .003 \\
\hline
\end{tabular}

Variable(s) entered on step 1: AGE, academics, household-members, income, distance

The response variable is motorcycle ownership (MCO). The log-odds of motorcycle ownership (Logit MCO) is given by: $\operatorname{Logistic}\left(M C_{o}\right)=f\left(A_{G}, A_{Q}, H_{M}, M_{I}, T_{D}\right)$

Where:

$A_{G}=$ Respondent's Age

$A_{Q}=$ Academic qualification of respondents

$H_{M}=$ Total number of household members

$M_{I}=$ Monthly household income

$T_{D}=$ Average Daily travel distance

From Table 2, the estimated model is given as:

$$
\operatorname{Logit}\left(M C_{o}\right)=-5.779-0.775 A_{Q}+0.357 H_{M}-0.508 M_{I}
$$

The model estimate shows that academic qualification of respondents, number of household members and monthly household income contribute significantly to the binomial logistic regression, that there is a 1.43 times likelihood of owning a motorcycle with a unit increase in the number of household members, while there is a reduction in the likelihood of owning a motorcycle by 1.66 times and 2.17 times for a unit increase in the average monthly income and academic qualification of household head respectively. However, the R square value obtained as shown in Table 3 indicate that $70.5 \%$ of the dependent variable is explained by the independent variables chosen, while $29.5 \%$ is explained by other variables not included in the model or captured by the field work. 
Table 3 - Model Summary

\begin{tabular}{lccl}
\hline Step & -2Log likelihood & $\begin{array}{l}\text { Cox \& Snell } \\
\text { R Square }\end{array}$ & $\begin{array}{l}\text { Nagelkerke } \\
\text { R Square }\end{array}$ \\
\cline { 2 - 4 } & $538.562 \mathrm{a}$ & .570 & .705 \\
\hline
\end{tabular}

\section{Conclusion}

The study examines the household factors which influence motorcycle ownership in Akure, the capital of Ondo State in South west Nigeria. Motorcycle ownership was studied at household level using house to house Questionnaire survey and Binomial Logistic Regression Model to analyse the data and determine the effect of the various factors on Households decision to own or not to own a motorcycle in the study area.

The model analyses shows that only academic qualification of household head, number of household members and average monthly income of household significantly influences motorcycle ownership across the zones. Both average monthly income of household and academic qualification of household head had a negative influence on motorcycle ownership, whereas number of household members has a positive relationship with motorcycle ownership. The influence of these factors signifies that a household is more likely to own a motorcycle with lower average monthly income, lower academic qualifications and a higher number of household members.

Since it has been found out that motorcycle ownership is influenced by low income earnings in the study area, it is therefore expected that this study will provoke further research into areas that will assess the viability of motorcycle as a means of low cost public transportation in a typical African city like Akure. However, the government at all levels should improve public transportation modes in other to reduce the hazards that are related with motorcycle modes.

\section{References}

Aderamo, A. J., and Olatujoye, S. (2013).Trends in Motorcycle Accidents in Lokoja, Nigeria. European International Journal of Science and Technology, 2(6), 251-261.

Hsu, T.P., and Lin, Y.J. (2007). Multinomial Logit Model of Motorcycle and Car Ownership in Taiwan. Proceeding of the Eastern Asia Society for Transportation Studies, 6.

Ogunmoriti, E., and Ige, A. D. (2013). Vehicle Ownership Models in Akure Metropolis, Ondo State. Unpublished B. Eng project, Federal University of Technology Akure, Ondo State, Nigeria.

Ogunsanya, A. A., and Galtima, M. (1993).Motorcycle in Public Transport Service in Nigeria: A Case Study of Yola Town. In J.S. Ikya (1st ed.) Urban Passenger Transportation in Nigeria, Ibadan: Heinemann, 191-207

Okoko, E. E. (2006). Quantitative techniques in urban analysis.Kraft Books Limited, Ibadan.

Owolabi, A.O., (2009). Para transit Modal Choice in Akure, Nigeria Applications of Behavioural Models. International Journal of Transportation Engineering.

Oyedepo O.J (2014). Predictive Model of Traffic Flow at Urban Road Intersection: A Case Study of Akure Metropolis; Unpublished Ph.D Thesis Submitted to School of Postgraduate Studies, Federal University of Technology Akure, Nigeria.

Oyesiku, O. O. (2002). "From Womb to Tomb". Proceedings of the 24th Inaugural Lecture, OlabisiOnabanjo University,Ago Iwoye. OOU Press.

Olubomehin, 0.0. (2012). The development and impact of motorcycles as means of commercial transportation in Nigeria. Research on Humanities and Social Sciences, 2(6), $231-239$.

Sadullah, A.F.M., and Leong, L.V. (2007). A Study on the Motorcycle Ownership: A Case Study in Penang State, Malaysia. Proceeding of the Eastern Asia Society for Transportation Studies, 6.

Tuan and Shimizu (2005). Modeling of Household Motorcycle Ownership Behaviour in Hanoi City. Journal of the Eastern Asia Society for Transportation Studies, 6, 1751 - 1765.

World Bank (2002). Cities on the move. A World Bank urban transport strategy review, Washington DC, United Front Publishers. 